\title{
Path Analysis of Psychological Capital Affecting Teachers' Innovative Behavior Based on Structural Equation
}

\author{
Yuqin Pan, Hongyu Diao, Shuangjie Li \\ College of economics and management, Beijing University of Technology, China, Beijing, 100124
}

Keywords: teacher; innovative work behavior; psychological capital; structural equation model; multi-group analysis

\begin{abstract}
Based on the hypothesis test of the theoretical model of teachers' innovative work behavior, this paper conducts multi-group analysis with psychological capital as the adjustment variable. The results show that the professional values, professional recognition and teaching ability of low psychological capital teachers have greater influence on innovative work behaviors; the influence of high and low psychological capital on teachers' innovative work behavior is mainly reflected in the effect of professional values on professional identity. In addition, the development of psychological capital and the establishment of the professional values of setting high moral values and cultivate person, which will help the construction of Chinese teacher human resources.
\end{abstract}

\section{Literature review}

In 1996, Amabile ${ }^{[2]}$ first proposed the behavior of individual innovation work, which is considered as the process of individual's successful transformation of creative ideas into behaviors. Since then, many researchers have carried out a lot of research on the behavior of innovative work, but there are big differences in the definition of teachers' innovative work behavior. The concept of innovative work behavior applied in this paper is the expansion and extension of the organizational field in the field of education. There are many researches on innovative work behaviors in the organizational field. Zhou and George ${ }^{[3]}$ proposed that individual innovation work behaviors include not only innovative ideas but also the promotion, development and implementation of innovative ideas. Liu Yun and Shi Jintao ${ }^{[4]}$ believe that innovative work behavior is a process in which individuals generate, introduce and apply beneficial, novel ideas or things in related work activities. It can be seen that innovative work behavior can be understood as a series of behaviors in which individuals generate novel ideas or schemes in their work, solve practical problems at work and achieve positive effects, including the generation, development and implementation of innovative ideas and so on.

\section{Data collection and reliability and validity test}

\subsection{Data collection and screening}

The research data mainly comes from the network research of teachers' system. According to the regional and economic development level, the teachers of primary and secondary schools and kindergartens in three prefecture-level cities in western China, central and eastern China are selected to research their professional values, professional recognition, psychological capital, teaching ability and innovative work behavior and other aspects. The measurement of psychological capital uses the PCQ-24 scale. The sample data was 235,660 copies and the valid data was 156,062 copies. (According to the lie test title score $>3$, the social appeal topic score $>5$, the answer time $<$ 1 second, determine the invalid questionnaire).

\subsection{Reliability and validity test}

Using SPSS21.0 software, the reliability and validity of the 11 observed variables and 2 latent variables were tested. The results are shown in Table 1. 
Table 1. Reliability and validity analysis results

\begin{tabular}{llll}
\hline & P value & KMO value & Cronbach's Alpha \\
\hline Professional values & 0.000 & 0.842 & 0.855 \\
Professional recognition & 0.000 & 0.664 & 0.670 \\
Teaching ability & 0.000 & 0.500 & 0.899
\end{tabular}

\section{Test of theoretical models}

\subsection{Model fit and matching degree}

According to the model hypothesis and the effective sample, there are three groups of ten observation variables in the study, which correspond to the three latent variables of professional values, professional recognition and teaching ability, and the innovative work behavior is the external manifestation of these three internal factors. In this paper, AMOS21.0 software is used as the analysis tool to fit the structural equations of the hypothesis model. The results show that the estimated parameters are good and are significant at $\mathrm{p}<0.001$ level (Table 1 ).

The chi-square value fit is not suitable due to the large number of samples[16]. Rong Taisheng ${ }^{[17]}$ and Hou Jietai ${ }^{[18]}$ considered the model fitting and matching degree test. In addition to the chi-square value, SRMR has more reference value than RMR (SRMR $<0.05$ ). In this study, SRMR, RMSEA, GFI, RFI, etc. all met the good matching degree results, and the overall good fit between the model and the data was good (see Table 2).

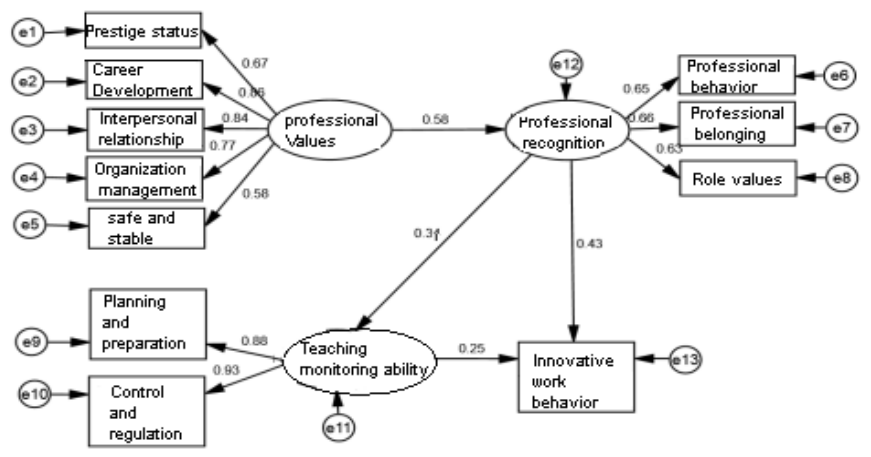

Figure 1. Theoretical model fitting results

Table 2. Summary of overall model fit test results

\begin{tabular}{cccc}
\hline Statistics & Adapted standard or threshold & Test result data & $\begin{array}{c}\text { Matching degree } \\
\text { judgment }\end{array}$ \\
\hline GFI & $>0.9$ & 0.959 & Yes \\
AGFI & $>0.9$ & 0.934 & Yes \\
RMR & $<0.05$ & 0.026 & Yes \\
SRMR & $<0.05$ & 0.0431 & Yes \\
RMSEA & $<0.08$ & 0.075 & Yes \\
NFI & $>0.9$ & 0.951 & Yes \\
CFI & $>0.9$ & 0.951 & Yes \\
IFI & $>0.9$ & 0.951 & Yes \\
PNFI & $>0.5$ & 0.709 & Yes \\
PCFI & $>0.5$ & 0.709 & Yes \\
\hline
\end{tabular}




\subsection{Model Hypothesis Test}

Hypothesis testing of the set theoretical model was performed using AMOS 21.0 software (Table 3 ). The three latent variables of occupational value, professional recognition and teaching ability all performed significantly at the $\mathrm{p}<0.001$ level, indicating that the four basic hypotheses of the hypothesis model were supported by the survey data.

Table 3. Structural model estimation results

\begin{tabular}{|c|c|c|c|}
\hline Hypothesis & $\begin{array}{c}\text { Standardization } \\
\text { coefficient }\end{array}$ & C.R.（t value） & conclusion \\
\hline $\begin{array}{c}\text { H1: professional Values } \rightarrow \text { Professional } \\
\text { recognition }\end{array}$ & 0.577 & 151.127 & accept \\
\hline $\begin{array}{c}\text { H2: Professional recognition } \rightarrow \text { Teaching } \\
\text { capacity }\end{array}$ & 0.336 & 98.824 & accept \\
\hline $\begin{array}{c}\text { H3: Professional recognition } \rightarrow \text { Innovative } \\
\text { work behavior }\end{array}$ & 0.650 & 181.381 & accept \\
\hline $\begin{array}{c}\text { H4: Teaching capacity } \rightarrow \text { Innovative work } \\
\text { behavior }\end{array}$ & 0.249 & 97.001 & accept \\
\hline
\end{tabular}

H1: occupational values---professional identity

H2: professional identity---teaching ability

H3: professional identity--- Innovation ability

H4: teaching ability---innovation ability

\subsection{Multi-group analysis of psychological capital}

The multi-group SEM analysis consists in evaluating whether the model adapted to a certain sample is also adapted to other different sample populations, that is, whether the hypothesis model proposed by the researcher is equal between different samples or whether the parameters are invariant. In this paper, multi-group analysis is based on psychological capital and the hypothesis model is fitted to the multi-group structural equation model to further examine the adaptation of the hypothesis model and explore the characteristics of the vectors in the hypothesis model in different groups.

The research selected data samples with psychological capital $\geq 5.18$ as a high psychological capital group, a total of 50206 sample sizes; selected data samples with psychological capital $\leq 4.68$ as a low psychological capital group, a total of 50471 sample sizes. Multi-group analysis was performed and the results showed that the model fit was excellent (Table 4). The path coefficients and factor loadings of the multi-group analysis results showed that the analysis results of the grouped samples and the overall samples were similar and the results of each group passed the test and performed significantly (Table 5).

Table 4. Summary of multi-group model fit test results

\begin{tabular}{cccc}
\hline Statistics & Adapted standard or threshold & Test result data & $\begin{array}{c}\text { Adaptation } \\
\text { judgment }\end{array}$ \\
\hline GFI & $>0.9$ & 0.963 & Yes \\
AGFI & $>0.9$ & 0.940 & Yes \\
RMR & $<0.05$ & 0.023 & Yes \\
SRMR & $<0.05$ & 0.0380 & Yes \\
RMSEA & $<0.08$ & 0.050 & Yes \\
NFI & $>0.9$ & 0.950 & Yes \\
CFI & $>0.9$ & 0.950 & Yes \\
IFI & $>0.9$ & 0.950 & Yes \\
PNFI & $>0.5$ & 0.708 & Yes \\
PCFI & $>0.5$ & 0.708 & Yes \\
\hline
\end{tabular}


Table 5. Multi-group model estimation results

\begin{tabular}{ccccc}
\hline \multirow{2}{*}{ Path } & \multicolumn{2}{c}{ High psychological capital } & \multicolumn{2}{c}{ Low psychological capital } \\
\cline { 2 - 5 } & Path coefficient & $\begin{array}{c}\text { C.R. } \\
\text { (t value) }\end{array}$ & $\begin{array}{c}\text { Path } \\
\text { coefficient }\end{array}$ & $\begin{array}{c}\text { C.R. } \\
\text { (t value })\end{array}$ \\
\hline $\begin{array}{c}\text { H1: Professional } \\
\text { Values } \rightarrow \text { Professional recognition } \\
\text { H2: Professional }\end{array}$ & 0.477 & 53.735 & 0.616 & 75.528 \\
$\begin{array}{c}\text { recognition } \rightarrow \text { Teaching capacity } \\
\text { H3: Professional } \\
\text { recognition } \rightarrow \text { Innovative work } \\
\text { behavior }\end{array}$ & 0.034 & 5.953 & 0.250 & 41.407 \\
$\begin{array}{c}\text { H4: Teaching capacity } \rightarrow \text { Innovative } \\
\text { work behavior }\end{array}$ & 0.143 & 32.435 & 0.273 & 58.265 \\
\hline
\end{tabular}

H1: occupational values---professional identity

H2: professional identity---teaching ability

H3: professional identity--- Innovation ability

H4: teaching ability---innovation ability

The multi-group results show that the path coefficient of teachers with low psychological capital is greater than that of teachers with high psychological capital and the two types of samples have the greatest influence in path $\mathrm{H} 1$ (professional recognition degree $\rightarrow$ occupational behavior tendency, factor load of high psychological capital) For 0.36, the factor load for low psychological capital is $0.68, \mathrm{t}=1.791, \mathrm{p}<0.10$ ). That is to say, teachers with low psychological capital have poor sense of professional recognition and responsibility, which is directly manifested by poor professional behavior and low performance of innovative work. This is because teachers with low psychological capital lack correct understanding of their own occupations and their professional honor and sense of responsibility are low. This directly leads to a lack of attention to students' enthusiasm and enthusiasm for learning and lacks review and evaluation of their own teaching processes and methods. Develop a complete teaching plan, develop and educational methods, achieve desired teaching goals and promote student innovation.

\section{Conclusion}

This paper systematically analyzes the relationship between professional values, professional recognition and teaching monitoring behaviors on teachers' innovative work behaviors and on the basis of psychological capital, the group of teachers, the path of psychological capital and its influence degree. For multi-group analysis, Main findings the level of psychological capital affect the performance of teachers' innovative work behaviors. Teachers must establish correct professional values, face up to and recognize their own occupations. On the other hand, in the process of teacher human resources development, teachers can be trained through training. Capital, improve teaching ability and innovative behavior and meet China's demand for teachers' human resources construction.

\section{References}

[1] Luthans F, Luthans K W, Luthans B C. Positive psychological capital: beyond human and social capital [J]. Business Horizons, 2004, 47(1): 45-50.

[2] Amabile T. Creativity in Context: Update to the Psychology of Creativity [J]. High Ability Studies, 1996(2): 100-101.

[3] Zhou J, George J M. When Job Dissatisfaction Leads to Creativity: Encouraging the Expression of Voice [J]. Academy of Management Journal, 2001, 44(4): 682-696. 
[4] Liu Yun, Shi Jintao. Research on the Influence Process of Organizational Innovation Climate on Employees' Innovative Behavior_—Based on the Analysis of Mediating Effect of Psychological Authorization[J]. China Soft Science, 2010(3): 133-144. 